\title{
Research and application of green assembled steel structure building system
}

(MCC Capital Engineering \& Research Incorporation Yantai Co., Ltd. Yantai, Shandong 264100)

\section{Introduction}

The so-called assembled steel structure building means all the components are firstly machined in the factory, which results in a large decrease in the volume of construction on the construction site, reduces pollution in the environment, and also substantially speeds up the construction period, passes standardized design-construction, thus fully ensuring the safety and quality of building construction, geared to the current development concepts of green, innovation, openness and coordination. Therefore, the enhancement of research on green assembled steel structure building system is of great significance.

1. Advantages of an assembled steel structure

\subsection{Flexible spatial arrangement}

Although there is not much difference between steel structures and concrete structures in terms of structure form, steels provide relatively high compressive strength and tensile strength and thus can be applied in some buildings with a larger span, which fully satisfies diversified requirements of different crowds for space. Moreover, the wall of this structure is an in-filled wall; hence, with regard to the structural arrangement, steel structures are more flexible and simpler than concrete structures.

\subsection{Green environmental protection, sustainable development}

In the steel structure, green environmental protection is again a very important characteristic. In the steel structure building, the steel structure is connected by attaching and assembling various components, therefore, it is more convenient to dismantle and build, and used steels can be recycled, reducing the production of building garbage. In addition, as the steel structure is constructed in assembly mode, the construction plant required won't be very big, the noise caused in the process of construction is relatively low and the influence on the residents adjacent to the construction site is relatively small. Generally speaking, by using this form, the level of green environmental protection of buildings can be improved, thus matching national

\subsection{Light dead weight and} large bearing capacity
Abstract: At present, energy savings and environmental protection are increasingly advocated in the process of social development, and developing green industries has been a problem about which the whole society is concerned. In the construction industry, green assembled steel structure building has the advantages of environmental protection and energy savings; therefore, it has been widely used in the real world with bigger development space. In the green assembled steel structure building system, the green assemble steel structure building takes building components or building functional units as a basic element and makes itself be characterized by production factorization and maintenance integration through combination of the elements. Based on that, the paper conducts a brief analysis on green assembled steel structure building system in hope of being able to offer a reference.

Key words: green assembled steel structure; building system; application

Published on 30th Sept,2017 
The characteristic of steel structure materials is lightweight and high strength; therefore, in the building steel structure construction, larger load can be borne just with fewer materials. By contrast, for concrete, to bear corresponding load, increasing the concrete section is needed, this in turn will make the dead weight of the structure become large. If the dead weight increases, adverse impact will be caused to the structural foundation, and if the dead weight of the structure decreases, the load borne will be small too, that way the requirements for the foundation will be lowered, meanwhile, the construction cost of foundation works can also be reduced.

\subsection{Better quality and excellent seismic performance}

As the assembled steel structure is produced by machining in the factory and subject to strict quality inspection during the exit-factory process, the quality of each component can be fully guaranteed. Besides, steels have higher plasticity and strength and better toughness, and thus exhibit big advantages in seismic resistance.

\section{Analysis of assembled steel} structure building system

\subsection{New "modularized and factorized" building system}

In assembled steel structure building system, modularized building system is highly representative and mainly includes box-type house and movable house. In these two types of houses, thin-walled steels or light steel structures are adopted, and the building envelope material is also flame resistant. The houses are easier to use, with relatively low construction cost.

Factorized steel structure building system abandons traditional building modes, utilizes quality management systems from manufacturing industry, and carries out a very strict examination on each procedure of every product from design to production to make each product able to comply with the standard. It not only improves quality, but also increases the building cost efficiency.

\section{2 "Industrialized housing" building system}

To effectively resolve beam column problems in traditional steel structural framing systems, some research institutes and enterprises developed "Industrialized housing" building systems for residential buildings, e.g., Hang Xiao Steel Structure Co., Ltd. developed a steel tube bundle combined structure system. In this system, steel tube bundles are formed with steel tube parts connected together in side-by-side connection mode, and inner steel tube bundle combined components formed through concrete pouring are used as lateral force resisting and bearing components; the steel beam uses $\mathrm{H}$-shaped steel; the floor used adopts assembled steel bar truss decks.

3. Application and development of green assembled steel structure building system

\subsection{Assembled steel structure} system $+\mathrm{PC}$ components

Although assembled steel structure building system has many advantages, there are also some problems in the actual application process. To effectively solve these problems, precast concrete can be used to improve productivity and fully ensure production quality during the construction process. Precast concrete is environmentally friendly and can be used in components like floor and stair, as a favorable supplement to the steel structure.

\subsection{Cross application of enclosure wall and construction practice}

Wall is an important part of buildings. In the construction process of frame structure, the enclosure wall is the final part, and it has been fully developed and improved to some extent in every aspect of functions, making it more durable. But walls have nothing in common with each other; therefore, each type of wall has different advantages and disadvantages. As a result, if it is desired to better solve this problem, the homogeneity of walls should be avoided. To able to match development requirements, various wall materials can be mixed and applied, so that they are fused together. 
3. Deep combination of process of BIM technology, it is assembled steel structure and BIM technology

1) Design stage of construction drawings and deepening drawings: in the assembled steel structure building, all the building products and parts can be expressed in a physical information digitalizing way according to the manufacturing requirements of factories, and thus can be directly offered to manufacturers. By establishing building information models, not only can the purpose of confliction inspection be reached, but also the effects of virtual construction can be made, and thus the basis of visualization are provided for the optimization of onsite construction; 2) Factory manufacturing stage: In the use process of BIM technology, it is manufacturing stage: In the use possibility to digest steel to some possible to directly input related information in the building information model into computer numerical control machine tools and intelligent robotics, and thus realize digital manufacturing; 3) Onsite installation stage: it is potential to utilize information-based technology to give feedback to steel structure manufacturing factories timely on error problems existing in the actual installation process, and adjust the machining of subsequent components to greatly improve installation accuracy, thus achieving the goal of refined management.

All in all, from the current point of view, the development of steel structure buildings provide the productsproduced in steel industry extent and accelerate capacity reduction, therefore, it is required to step up efforts to improve the quality of steel structure building on the existing basis to make it even satisfy people's requirements, and to endeavor to seek for bigger development in the market with high quality, green, energy saving and environmental protection.

\section{References}

[1] Cao Yang, Chen Feibin, Long Ye, Discussion on the Detailed Design of Assemble Steel Structure Building [J]. Steel Structure, 2016, 02:72-76.

[2] Wang Zhen, Current Status of the Development of Maintenance System for Assembled Steel Structure, Brick-tile, 2016, 05:47-49. 